\title{
As cidades de Juan Carlos Onetti
}

\author{
The cities of Juan Carlos Onetti \\ Iuri Almeida Müller \\ Pontifícia Universidade Católica do Rio Grande do Sul - Porto Alegre, Rio Grande do Sul, Brasil
}

$\diamond$

\begin{abstract}
Resumo: Este trabalho busca analisar a forma com que o espaço urbano é representado na primeira fase de escritura do autor uruguaio Juan Carlos Onetti, bem como os elementos utilizados na construção literária de Santa María, cidade ficcional criada por Onetti e que está presente em seus contos e romances, como $A$ vida breve. Da mesma forma, a partir da observação de mapas, o ensaio busca compreender como o deslocamento dos personagens, nos contos "Regreso al sur", de Onetti, e "El sur", de Jorge Luis Borges, explicita questões culturais e geográficas referentes à cidade moderna - neste caso, a cidade de Buenos Aires.
\end{abstract}

Palavras-chave: Conto; Espaço narrativo; Literatura e cidades; Juan Carlos Onetti; Jorge Luis Borges

\begin{abstract}
This research investigates the way how urban space is represented on the first phase of writing of the Uruguayan author Juan Carlos Onetti, so as the elements used on the literary construction of Santa María, fictional city created by Onetti that is present in his tales and novels as A vida breve. Similarly, from observation of maps, this essay looks to understand how the displacement of the characters, in the tales "Regreso al sur", by Onetti, and "El sur", by Jorge Luis Borges, shows cultural and geographic questions about the modern city - in this case, the city of Buenos Aires.
\end{abstract}

Keywords: Tale; Narrative space; Literature and cities; Juan Carlos Onetti; Jorge Luis Borges

No final dos anos 1940, Juan Carlos Onetti (19091994) estava às voltas com a escritura de La vida breve e vivia em Buenos Aires. O romance, por algum motivo, resistia às mãos do escritor e permanecia incompleto. Conta Dolly Onetti, companheira de Juan Carlos nas últimas décadas de vida, que a entrada de uma personagem feminina na história, inspirada na própria Dolly, acabaria por destravar a escritura do livro. "Juan me confesó que había reanudado la escritura con pasión, con alegría, con alivio"1, ela escreveu. La vida breve seria publicado em 1950 e hoje é tido como o mais importante romance do autor, e talvez seja também o mais estudado. Ali apareceriam pela primeira vez as ruas de Santa María, a cidade ficcional criada por Onetti e que se repetiria, com seu mapa e seus habitantes, no restante da obra. Santa María, cidade portuária e um tanto enferrujada; povoado provinciano cortado pelo vento e repleto de marcas de umidade; com Santa María nasce um universo próprio, mundo criado pela e para a literatura.

\footnotetext{
Prefácio a La vida breve (2013).
}

Em La vida breve, Santa María surge como salvação: imaginar e escrever é o que Juan María Brausen, protagonista e narrador do romance, precisa para sobreviver numa rotina de trabalho medíocre e melancolia nas relações pessoais. Brausen vive em Buenos Aires com Gertrudis, sua mulher, num apartamento da rua Chile. Ganha a vida com pequenos trabalhos para uma agência de publicidade, com a qual mantém um vínculo que se localiza entre a necessidade e o desinteresse. $\mathrm{O}$ passado dos personagens está em Montevidéu, do outro lado do Rio da Prata. Lá se conheceram e ainda residem boa parte das recordações. Para Brausen, a fuga de um cotidiano que parece se eternizar em dias cinzentos e quase sem acontecimentos, agravado pela falta de dinheiro, pode estar num trabalho para Julio Stein, o seu contato na agência de publicidade.

Juan María Brausen pensa que pode escrever e que com um roteiro de cinema que convença Stein haverá dinheiro e evasão da realidade. Assim, estará longe da tristeza de Gertrudis, das noites vazias, do calor de primavera que atinge Buenos Aires. Pensa que pode 
escrever sobre a cidade de Santa María, onde esteve por um dia e que agora retorna na memória:

No llores -pensaba-, no estés triste. Para mí es todo lo mismo, nada cambió. No estoy seguro todavía, pero creo que lo tengo, una idea apenas, pero a Julio le va a gustar. Hay un viejo, un médico, que vende morfina. Todo tiene que partir de ahí, de él. Tal vez no sea viejo, pero está cansado, seco. Cuando estés mejor me pondré a escribir. Una semana o dos, no más. No llores, no estés triste. Veo una mujer que aparece de golpe en el consultorio médico. El médico vive en Santa María, junto al río. Sólo una vez estuve allí, un día apenas, en verano; pero recuerdo el aire, los árboles frente al hotel, la placidez con que llegaba la balsa por el río. Sé que hay junto a la ciudad una colonia suiza. El médico vive allí, y de golpe entre una mujer en el consultorio. Como entraste tú y fuiste detrás del biombo para quitarte la blusa (...) (2013, p. 31).

Em La vida breve, assim como em quase toda a obra de Juan Carlos Onetti, a literatura está orientada num eixo que se forma sobre três cidades: Montevidéu, a cidade em que nasceu, Buenos Aires, o lugar em que viveu e escreveu por muitos anos, e Santa María, cidade ficcional, fundada no trecho acima, no pensamento de Juan María Brausen que não alcança Gertrudis.

"Hay un viejo, un médico, que vende morfina. Todo tiene que partir de ahí, de él". E depois: "Veo una mujer que aparece de golpe en el consultorio médico". O médico é o doutor Díaz Grey, logo saberemos, já que os escritos de Brausen ganham continuidade e Santa María se forma no papel. O consultório de Díaz Grey, imagina Brausen que por sua vez imagina Onetti, fica em frente à praça central do povoado e das suas janelas o médico consegue observar o ir e vir dos habitantes pelas ruas principais; por ali também se erguem o hotel, a estátua equestre, a biblioteca em ruínas, o clube social, a igreja, o café. Nada muito distinto da organização espacial das cidades de província, ao menos no que diz respeito às cidades do sul do mundo. A mulher que aparece sem aviso no consultório de Díaz Grey é Elena Sala, a forasteira, que viaja a Santa María para obter alguns favores do médico. Elena hospeda-se no hotel da praça e espera a chegada do marido, que deve desembarcar logo da balsa que parte de Buenos Aires. Ao passo em que La vida breve cresce, a Santa María ficcional de Onetti ganha solidez. O processo de construção, construção literária e de um espaço narrativo, perdura e avança: Santa María é também o cenário de El astillero (1961), Juntacadáveres (1964) e Dejemos hablar al viento (1979), entre outros romances, e de contos como "Jacob y el otro" e "El álbum". Com Santa María, Onetti inauguraria uma sequência de lugares ficcionais que caracterizariam, mais tarde, a literatura latino-americana.
Em 1989, a editora Record traduziu e organizou dezenove dos contos de Onetti numa edição que intitulou, no Brasil, de Tão triste como ela e outros contos. $\mathrm{O}$ tradutor Eric Nepomuceno abre o livro com um texto que chamou de "Notas para um perfil". Nepomuceno, depois de lamentar que Onetti, já lido e pesquisado em boa parte dos países do continente, continuava sendo um escritor quase que desconhecido no Brasil, pinça um dos traços do escritor uruguaio - justamente a fundação literária de Santa María: “Onetti, entre tantas coisas, foi possivelmente o primeiro autor a criar na literatura latinoamericana contemporânea um mundo ficcional com vida própria, capaz de transcender sua circunstância geográfica, histórica, social: Santa María" (ONETTI, 1989, p. 8). No mesmo texto, o tradutor recorda a frase em que, numa entrevista, Juan Carlos Onetti justificou a criação de uma cidade para a sua ficção. Na resposta, aparecem as três cidades que formam o eixo geográfico-literário da obra de Onetti; triângulo que une duas cidades do Rio da Prata com um lugarejo imaginário que se formou num ponto impreciso do mapa:
Eu vivi muitos anos em Buenos Aires, e de alguma maneira a experiência de Buenos Aires está muito presente em minha obra; mas muito mais que Buenos Aires está presente Montevidéu, a melancolia de Montevidéu. Por isso fabriquei Santa María: fruto da nostalgia da minha cidade. Fora dos meus livros Santa María não existe. Se existisse, com certeza eu faria lá a mesma coisa que faço hoje. Naturalmente, inventaria uma cidade chamada Montevidéu (1989, p. 8).

Para a pesquisadora Rocío Antúnez, a obra de Juan Carlos Onetti carrega uma forma de narrar que atenta para o espaço urbano (a cidade moderna) e se insere profundamente neste espaço: "Lo nuevo en los relatos de Onetti - y entonces novedoso en la literatura rioplatense es la escenificación de la percepción urbana en el interior de una mente capaz de verbalizarla simultáneamente a su ocorrencia" (ANTÚÑEZ, 2013, p. 99). Antúnez se refere aos primeiros contos de Onetti, escritos na década de 1930 e publicados primeiramente em jornais de Buenos Aires como o La Prensa. Este é o caso de contos como "Avenida de Mayo - Diagonal - Avenida de Mayo", de janeiro de 1933, o primeiro relato que Onetti pôde publicar. Em "Avenida de Mayo...", o protagonista Victor Suaid caminha por algumas das ruas cêntricas de Buenos Aires, cidade que se modificou de maneira drástica naqueles anos. $\mathrm{Na}$ década de 1930, já era possível notar na capital argentina a transformação causada pelos milhares de imigrantes que chegavam de distintos navios europeus, as alterações no ritmo de vida e de trabalho, a construção de prédios altos que começavam a alterar a arquitetura da cidade, a presença de novas linguagens nas experiências do cotidiano, etc. 
Ao caminhar pela rua Florida, Victor Suaid se vê entre as tantas mensagens de uma Buenos Aires cosmopolita e, enquanto anda, aparentemente sem rumo certo, se depara com letreiros de propaganda, anúncios de teatro e cinema estrangeiros, manchetes de jornal em caixa alta, edifícios de vinte andares e com uma multidão que preenche por inteiro as ruas ainda estreitas. Paradoxo da modernidade, Suaid está ao mesmo tempo acompanhado (ao seu lado, passam milhares de pessoas, e talvez ele não consiga reconhecer o rosto sequer de uma delas) e inteiramente sozinho. "Entonces se vio, pequeño y solo, en medio de aquella quietud infinita que continuaba extendiéndose" (ONETTI, 2009, p. 32), escreve o narrador. A mesma percepção sensível da cidade em que se vive e que é modificada todos os dias aparece em contos como "El posible Baldi" (1936) e, mais tarde, em "Regreso al sur" (1949). Em comum, os três contos mencionados se passam em Buenos Aires; quando a cidade não é mencionada, podemos inferir seu nome por numerosos pontos de referência: estão ali nomes de ruas, de praças, a menção a algum bairro ou teatro. Buenos Aires, nos três contos, não é apenas pano de fundo para uma narrativa que se movimenta independente do espaço em que se insere. Para Onetti, apropriar-se das questões urbanas e problematizar o habitante das cidades é uma das funções da literatura a ser escrita naqueles anos. Trata-se de uma proposta literária.

A atenção para a cidade é, inevitavelmente, escolha e exclusão; ao direcionar a literatura para Buenos Aires e Montevidéu, Juan Carlos Onetti acaba por se distanciar de uma tradição literária do Rio da Prata que desde muito cedo voltou os olhos não para a cidade, mas para o campo. Ainda que a enorme maioria dos escritores vivesse em cidades e não em povoados rurais, a literatura dos dois países teve em seus textos fundacionais a figura do gaucho e o campo como preocupações. Em Juan Carlos Onetti: caprichos con ciudades (2013), Rocío Antúnez busca os artigos nos quais Onetti, também articulista, defende a opção pelas cidades como proposta literária. Em 1939, anos depois, portanto, da escritura e da publicação de contos como "Avenida de Mayo - Diagonal - Avenida de Mayo", Onetti, sob o pseudônimo de Periquito, el Aguador, escreve para o semanário Marcha o artigo "Literatura nuestra". Para Onetti, diante da predominância de relatos rurais,

Montevideo no existe. Aunque tenga más doctores, empleados públicos y almaceneros que todo el resto del país, la capital no tendrá vida de veras hasta que nuestros literatos se resuelvan a decirnos cómo y qué es Montevideo y la gente que habita. Y aquí no cabe el pretexto romántico de falta de tema. Un gran asunto, el Bajo, se nos fue para siempre, sin que nadie se animara con él. Este mismo momento de la ciudad que estamos viviendo es de una riqueza que pocos sospechan. (2013, p.20).
Montevidéu vive um momento rico e disso poucos suspeitam, escreve Onetti, que enumera em seguida três razões: a chegada de imigrantes, por vezes de origens quase desconhecidas para os locais, a transformação do aspecto urbano, já que por aqueles dias um edifício alto era construído ao lado de uma velha casa gradeada e, ainda, a mudança produzida na mentalidade dos habitantes. No fragmento acima, Onetti menciona que "un gran asunto, el Bajo, se nos fue para siempre, sin que nadie se animara con él". "El Bajo" era um bairro de Montevidéu, situado nas proximidades de onde ainda hoje se encontra a Ciudad Vieja, e que acabou demolido em uma das reformas urbanas que o poder público levou adiante na época. No Baixo de Montevidéu, zona antiga e pobre, sobreviviam pensões, cortiços, pequenas oficinas, bares e prostíbulos. Para Onetti, por ali seria possível encontrar riquíssimo material humano e literário. Ambientes assim podem ser vistos em muitos dos textos do escritor montevideano. Nesses lugares, Onetti não buscou elementos de sordidez ou de caricatura, mas sim histórias de seres desenraizados, estrangeiros na própria cidade, e de homens e mulheres num constante movimento de viagem, de abandono e retorno. Algo assim Onetti propunha que os escritores buscassem no Baixo de Montevidéu, antes da sua demolição, e que ele mesmo fez na novela $E l$ pozo, de 1939, a primeira da sua obra.

Pensões e cortiços se multiplicaram em Buenos Aires e em Montevidéu, como em outras capitais latinoamericanas, nas primeiras décadas do século XX. Surgem como consequência, mais do que nada, de um crescimento populacional pouco planejado, acentuado pela chegada de imigrantes e pelo êxodo das populações nacionais, do interior para as metrópoles. Rocío Antúnez escreve que, nestes lugares, a distinção entre os espaços de convivência e os que reservam momentos de intimidade é pequena, e que os limites se dissolvem na organização do local. "La vida privada se adelgaza y refugia en el cuarto, lugar destinado a gran parte de las actividades domésticas, incluída la higiene personal. El cuarto funciona así como una fracción, un interior incompleto, dependiente del afuera" (ANTÚÑEZ, 2013, p. 127), diz, e o "afuera" se caracteriza por ambientes como pátio, área de lavar e estender roupas, banheiros coletivos, etc. É nesta situação em que caminham, pensam e escrevem alguns dos personagens de Juan Carlos Onetti.

No Rio da Prata, bairros como o Baixo de Montevidéu cresceram nas cercanias do porto e em Buenos Aires há alguma semelhança com os exemplos de La Boca, Barracas e San Telmo, bairros localizados na região sul da cidade. Na capital uruguaia, ainda é possível encontrar vestígios do que Onetti transformou em literatura. Roupas estendidas nas janelas, apartamentos compartilhados por membros de distintas famílias, edifícios antigos e 
afastados das zonas tradicionalmente residenciais da cidade podem ser vistos, hoje, em algumas das ruas da Ciudad Vieja, como 25 de Mayo, Cerrito e Piedras, três vias próximas ao antigo porto. Mesmo décadas depois do que Onetti observa como indício de um tempo de transformações, vemos rastros de pessoas que buscam, muitas vezes sozinhas, melhores condições de vida e trabalho nas grandes cidades, e que acabam por habitar, como nos anos 1930 e 1940, regiões que se aproximam do estado de abandono.

De Montevidéu para Buenos Aires, outra vez. Em "Literatura nuestra", o artigo já mencionado, Onetti, após evidenciar a predominância de temas rurais numa literatura escrita por autores que contraditoriamente vivem nas cidades, convida os seus pares: "es necesario que nuestros literatos miren alrededor suyo y hablen de ellos y de su experiencia. Que acepten la tarea de contarnos cómo es el alma de su ciudad" (apud ANTÚÑEZ, 2013, p.20). A alma da cidade, mais do que a cor local, pode ser o punhado de experiências e situações que se estende a boa parte dos habitantes de um lugar. Em "Regreso al sur", conto de 1949 e que se passa em Buenos Aires, Juan Carlos Onetti se arrisca a ingressar numa questão presente no cotidiano dos bonaerenses. "Regreso al sur" se ocupa da fronteira criada pela avenida Rivadavia, que divide a cidade de Buenos Aires em duas partes, distintas cultural e socialmente. De um lado, está a cidade antiga e, segundo Jorge Luis Borges, "mais firme"; do outro, ao norte, os bairros que cresceram depois e se desenvolveram com maior distância do imaginário criollo.

Horacio, personagem de "Regreso al sur", ignora desde o carnaval de 1938 os acontecimentos que tiveram lugar na parcela sul de Buenos Aires. Vive e se orienta apenas pelas placas e referências do norte desde que a sua mulher, Perla, abandonou a pensão em que viviam. Nas caminhadas noturnas com o filho Walter e o sobrinho Óscar, Horacio costumava ir até o limite imaginário e então retornar, como que contornando um muro que impedisse a passagem para os bairros do sul:

Sin hablar nunca de aquello, Óscar tuvo que enterarse de que la ciudad y el mundo de tío Horacio terminaban en mojones infranqueables de la calle Rivadavia; y todos los nombres de calles, negocios y lugares del barrio sur fueron suprimidos y muy pronto olvidados. De manera que cuando alguien los nombraba junto a él, tío Horacio parpadeaba y sonreía, sin comprender, pero disimulando, esperando con paciencia que la historia o los personajes cruzaron Rivadavia y él pudiera situarlos (2009, p. 121).

Perla se encontra na cidade que, depois do carnaval de 1938, se tornou parte de um território estrangeiro, esta Buenos Aires do sul que a Horacio não dizia mais respeito. A narrativa se desenvolve com a aceitação da existência do muro, de uma fronteira que no conto se estende à obsessão de um dos personagens. Para Juan Carlos Onetti, a linha que corta Buenos Aires ao meio, mais do que limite geográfico, é também definidora de rumos - e em "Regreso al sur", passar de um lado para o outro pode ser o ponto de inflexão da narrativa.

Ao longo da trajetória pessoal de Onetti, foram várias as idas e vindas de um lado para o outro do Rio da Prata. Juan Carlos Onetti, montevideano de nascimento e habitante de Buenos Aires durante parte importante da vida de escritor, não se enraizou de maneira definitiva em nenhum dos dois lugares. A permanência se deu, tempos depois, longe do sul do continente, em Madrid, quando a ditadura militar obrigou-o a buscar o exílio na capital espanhola. Já em tempos de democracia restaurada, Onetti optou por não retornar e então fez do desterro o lugar escolhido para passar o final da vida.

A viagem constante, é possível desconfiar, deixou marcas na sua obra, e é certo que modificou o seu olhar para o espaço em que vivia. As circunstâncias de despedidas e regressos fizeram com que Onetti fosse um pouco estrangeiro na Montevidéu natal e também em Buenos Aires, ou suficientemente forasteiro para impedir que o olhar se contaminasse sem volta pelos vícios e repetições dos lugares de sempre. Há algo deste desarraigamento na construção dos seus personagens, que parecem estar em muitas situações como que de passagem, à espera de um evento ou de uma impossibilidade que forcem o instante da viagem, da partida, e então se tenha que ir embora outra vez.

Em La vida breve, a ideia da evasão se dá não apenas na literatura, mas também de modo espacial. Gertrudis e Brausen relembram constantemente os anos em que viveram em Montevidéu, e por vezes imaginam como teria sido a vida se houvessem permanecido naquele lugar. Gertrudis, após dias de desolação, acaba por viajar a Temperley, pequena cidade da Província da Buenos Aires, para estar por perto da mãe e escapar da atmosfera impregnada de calor e tristeza do apartamento da rua Chile: "un día cualquiera ella pensó con una novedosa ansiedad en su madre, en la vieja que meditaba en su própria inutilidad en su casa de Temperley; estuvo segura de la confortación y de la perdurable Gertrudis joven que iba a encontrar en Temperley, junto a su madre" (ONETTI, 2013, p. 79). E Santa María, por sua vez, é descrita com características de uma cidade de passagem e a menção ao hotel e seus hóspedes é um artifício constante. No trecho seguinte, Brausen, decidido que o roteiro de cinema para Julio Stein poderia ser a salvação a curto prazo das suas inquietações, descreve velozmente a composição de Santa María, com o "flamante" hotel como a construção em destaque: 
Además del médico, Díaz Grey, y de la mujer - que desaparecía detrás del biombo para salir con el busto desnudo, volvía a esconderse sin impaciencia y regresaba vestida -, tenía ya la ciudad donde ambos vivían. (...) Tenía ahora la ciudad de provincia sobre cuya plaza principal daban las dos ventanas del consultorio de Díaz Grey. Sigilosamente, lento, salí de la cama y apagué la luz. Fui caminando a tientas hasta llegar al balcón y palpar las maderas de la celosía, corrida hasta mitad. Estuve sonriendo, asombrado y agradecido por que fuera tan fácil distinguir una nueva Santa María en la noche de primavera. La ciudad con su declive y su río, el hotel flamante y, en las calles, los hombres de cara tostada que cambian, sin espontaneidad, bromas y sonrisas (2013, p. 34).

Ser estrangeiro para se deparar com os elementos que se configuram como invisíveis para nativos e habitantes: esta é uma ideia que encontramos em Walter Benjamin, filósofo e viajante, que escreveu e pensou sobre as cidades em que esteve. Benjamin passou de Paris a Moscou, por Nápoles e Marselha, mas é sobre a sua Berlim natal que se ocupa desta espécie de desnaturalização que permite se aproximar do inefável. Em Zona urbana, Martín Kohan individualiza as percepções urbanas do filósofo alemão e se centra sobre cada um dos pontos geográficos relevantes para a obra de Benjamin. É quanto a Berlim que Walter Benjamin escreve sobre duas necessidades: a de aprender a perder-se e a de adquirir uma mirada que se aproxima da visão do estrangeiro, capaz de enxergar com curiosidade e estranhamento o que está à disposição dos olhos no cotidiano.

Para Benjamin, perder-se em Paris, a cidade moderna que aparece como exemplo das transformações europeias, metrópole de ruas povoadas por multidões, não é tarefa difícil; em Moscou, onde até mesmo as mais simples indicações de sentido das ruas é dificultada pelo hermetismo do idioma, perder-se, por sua vez, é quase uma regra. $\mathrm{O}$ conhecimento de se ver perdido, para assim construir um novo eixo de localizações - descobrir uma cidade nova na própria cidade em que nasceu - serve exatamente para Berlim. Escreve Martín Kohan que "para aprender a perderse en Berlín hay que aprender a extrañificarla. Sólo cuando se consigue convertirle en una ciudad extraña y poco familiar, llega a ser posible perderse en ella, y que ese extravío se deba a una destreza premeditaba y no a las limitaciones y a las dificultades del desorientado" (KOHAN, 2004, p. 61), e este raciocínio acompanhará as caminhadas de Benjamin por Berlim, andanças por vezes a esmo, e em outras ao encontro de casas e bairros que remetem a uma infância já distante, que se farão presentes nos textos de Infância em Berlim.

Em cada um dos textos curtos, a capital alemã parece banhada por uma luz nova, por uma iluminação de descobrimento (mesmo quando na rua havia escuridão), através de uma mirada possível apenas para quem vê a cidade pela primeira vez. É o caso deste trecho de "Tarde de inverno":

\begin{abstract}
às vezes minha mãe me levava para fazer compras em tardes de inverno. Era uma Berlim escura e desconhecida que, à luz de gás, se estendia à minha frente. Ficávamos no antigo Oeste, cujos arruamentos eram mais uniformes e despretensiosos que os preferidos posteriormente. Àquela hora já não se podia perceber com clareza as sacadas e as colunas, mas nas fachadas havia luz. Fosse por causa das cortinas de musselina, fosse por causa das venezianas ou da camisa da lâmpada de gás suspensa, aquela luz pouco revelava dos aposentos iluminados. Não tinha a ver com nada, a não ser consigo mesma. Atraía-me e deixava-me pensativo. Ainda hoje isso me acontece na memória (1995, p. 127).
\end{abstract}

A atenção microscópica e o exercício de se pensar estrangeiro num lugar conhecido de antemão são situações válidas tanto para Benjamin como para Onetti. No caso do escritor uruguaio, as constantes mudanças entre as duas maiores cidades do sul do continente e o esforço de levar para a ficção lugares ignorados da cidade fazem parte do mesmo fenômeno. Juan Carlos Onetti não se acostuma com o que vê em Buenos Aires e Montevidéu e espera do ambiente urbano uma riqueza que ainda está por ser descoberta; assim, espaços como pensões e cortiços, como o Bajo montevideano, passam das sombras para a literatura.

\section{O muro invisível da avenida Rivadavia (e o custo das travessias)}

Na primeira parte deste ensaio, quando o foco estava sobre as primeiras narrativas urbanas de Juan Carlos Onetti, escritas na década de 1930, foi possível perceber que a cidade moderna produzia nos observadores deste novo cenário sensações como estupefação, fascinação, temor, surpresa e dúvida. Vista mais do que nada como um espaço novo, e portanto ainda não assimilado por inteiro, a cidade causava reações contraditórias e intensas: se por um lado assustava com o seu ritmo acelerado e o surgimento de novos elementos (tanto físicos como subjetivos), ao mesmo tempo seduzia a quem estava disposto a tratá-la como objeto da sua ficção. Tal paradoxo que se constitui pelo espanto e a atração não é inteiramente inédito: décadas antes, no contexto europeu, as contradições causadas pela cidade moderna estão presentes mesmo na poesia lírica francesa. Na América Latina, e mais precisamente em Buenos Aires, o espaço em que se inserem os contos de Onetti aqui trabalhados, esse processo se dá de maneira distinta - e talvez seja preciso falar em "modernidade periférica", como sugeriu Beatriz Sarlo. 
Em Modernidade periférica: Buenos Aires 1920 e 1930, Sarlo se debruça sobre as transformações urbanas, mediante processos sociais e da cultura, e o impacto dessas mudanças na produção literária. É interessante pensar que muitos dos contos escritos por Onetti neste período são ambientados em Buenos Aires, e não em Montevidéu (Santa María ainda não havia surgido da caneta do escritor), visto que as modificações mais evidentes no contexto urbano chegam primeiro, e com maior intensidade, justamente na margem argentina do Rio da Prata. Em poucos anos, o mapa da cidade será outro, e andar pelas ruas exigirá outra velocidade e mesmo outros meios de transporte. Por sua vez, o centro se abrirá para novas experiências e linguagens e, pouco a pouco, esses ventos também alcançarão os bairros, ainda que de maneira heterogênea. Escreve Beatriz Sarlo no capítulo intitulado "Buenos Aires, cidade moderna", quando recorda as aguafuertes porteñas escritas por Roberto Arlt, que na época

o passante cruza uma cidade cujo traçado já foi definido, mas que ainda conserva muitas partes sem construções, terrenos baldios e ruas sem calçada. Os cabos da iluminação elétrica, porém, já haviam substituído, em 1930, os antigos sistemas a gás e a querosene. Os meios de transporte modernos (...) haviam se expandido e se modificado; em 1931, em meio a um escândalo denunciado por alguns jornais, o sistema de coletivos foi legalizado. Vivese a cidade numa velocidade sem precedentes e os deslocamentos rápidos não provocam consequências apenas funcionais. A experiência da velocidade e a experiência da luz moldam um novo elenco de imagens e percepções: quem tinha pouco mais de vinte anos em 1925 podia se lembrar da cidade da virada do século e comprovar as diferenças $(2010$, p. 35).

Essa cidade, a que recebe o impacto da modernização e tem, entre os seus habitantes, mais de um terço de imigrantes, como era o caso da Buenos Aires da década de 1930, é o espaço urbano de contos como "Avenida de Mayo - Diagonal - Avenida de Mayo", como se escreveu no primeiro capítulo. Após a publicação dos primeiros relatos e fiel ao compromisso que havia assumido (de levar para a ficção os temas da cidade que crescia), Juan Carlos Onetti não se distanciou do espaço urbano na sua ficção. Um conto da década seguinte, já mencionado de modo veloz na primeira parte deste ensaio, é um exemplo rico da escritura de Onetti num tempo posterior à época da estupefação e da fascinação causadas pela modernidade. É o caso de "Regreso al sur", de 1946, conto que se detém sobre uma cidade já assentada sobre suas peculiaridades regionais e traços culturais distintos, que variam conforme se observa o mapa do lugar.
Já havia em Buenos Aires, antes de 1946, suficientes identidades locais para que se pudesse falar de uma "cultura de bairro". Tais identidades se firmam na primeira metade do século XX e podem ser vistas em diversas manifestações culturais, como o futebol, o carnaval e a forma com que se tratava a política. A "cor local" de Buenos Aires era, na verdade, formada por distintos tons, e o caminhante encontraria mais dissonâncias do que semelhanças em lugares como Belgrano e Barracas, Palermo e La Boca. Bairros como Boedo, por exemplo, se orgulhavam de certa autossuficiência cultural: os seus habitantes eram, em grande parte, torcedores do Club Atlético San Lorenzo, frequentavam o carnaval do bairro e destinavam boa parte do tempo para os cafés e os bares daquelas ruas. $\mathrm{O}$ mesmo vale para lugares como Villa Crespo, Flores, Palermo, Floresta, com particularidades em suas principais esquinas. Distintas linhas, imaginárias ou não, cortavam Buenos Aires e definiam, em seus limites, a vida cultural e social dos que ali viviam.

Se foi formada no início do século XX e se assentou no mapa da cidade nas décadas seguintes, a identidade de cada bairro de Buenos Aires permanece em construção ao longo do tempo. Mesmo hoje, com a cidade atravessada por novos fluxos de imigração, pela abertura de largas autopistas e a remoção de moradias populares durante a última ditadura militar, pelas sucessivas crises econômicas e o enfraquecimento dos vínculos comunitários, Buenos Aires preserva tais identidades - ainda que por vezes estejam mais bem guardadas nas letras de tango (há um tango de Dante Linyera para Boedo, um de Carlos Lucero para Parque Patricios e uma composição de Juan Villalba para Palermo, para ficar só com três exemplos) ou na memória dos habitantes de outro tempo. É justamente esse recorte interno de Buenos Aires, formado por linhas reais - definidas por ruas e avenidas - e imaginárias, que aparece com o conto "Regreso al sur", escrito em 1946 por Juan Carlos Onetti.

Paralelamente ao eixo da geografia da cidade, Onetti traça o desencontro amoroso entre Horacio e Petra, um casal que vivia numa pensão situada na avenida Belgrano. No sábado de carnaval de 1938, Horacio e Perla caminharam, como faziam costumeiramente, pela avenida Belgrano e então pelas ruas Tacuarí e Piedras. Essas são vias do bairro de San Telmo, na região sul de Buenos Aires. Através da observação de Óscar, sobrinho de Horacio, o leitor saberá que o convívio do casal se interrompe ainda naquela semana festiva: na terça-feira de carnaval, uma carta, mantida em cima da mesa da pensão por um resignado Horacio, informa que Perla não viverá mais naquele lugar. Desde então, a estreita vida da família se modifica, bem como a relação com a cidade de Buenos Aires. Horacio e Óscar partem para uma outra 
pensão, mais ao norte, situada na esquina entre a avenida Corrientes e a rua Paraná, em pleno centro.

A partir desse momento, as caminhadas em direção ao sul são suspensas bruscamente. $\mathrm{O}$ costume de andar pelas ruas nas noites quentes permanecerá, mas até certo limite: os passos não podem ultrapassar a avenida Rivadavia, linha que corta a metrópole. A primeira menção em "Regreso al sur" ao limite da Rivadavia se dá através de Walter, filho de Horacio, que por vezes frequenta a pensão: "La valla de la calle Rivadavia se levantó gracias a Walter. No se animó a decirlo directamente al viejo; estaba detrás del tío Horacio y habló dirigiéndose a Óscar, que se ponía la corbata frente al espejo. - Vi a Perla en un café de la avenida. No me dijo nada especial, pero está bien" (ONETTI, 2011, p. 120). A avenida mencionada no conto é a Avenida La Plata, uma das principais passagens do sul de Buenos Aires, reconhecida por abrigar cafés, teatros e cinemas ao longo dos seus quarteirões. Perla havia ultrapassado a fronteira e se estabelecido no sul; passou a viver com um homem que tocava guitarra num café espanhol da avenida e, agora, estava separada de Horacio por uma espécie de linha invisível que impedia o contato entre os dois.

Onetti empregará em diversas ocasiões palavras como "valla" (cerca), "mojones infranqueables" (algo como marcações de fronteira), "valla invisible" e "muro invisible" para a linha desenhada pela avenida Rivadavia. A importância desta via da cidade de Buenos Aires se dá tanto de maneira pragmática como subjetiva - e, neste caso, os dois campos certamente se tocam. Em primeiro lugar, a Rivadavia corta Buenos Aires na metade do seu território e se estende de uma ponta a outra, de leste a oeste. Ao longo do seu trajeto, passam mais de oitenta linhas de ônibus, funcionam onze estações de metrô e mudam de cor aproximadamente cem semáforos. Todas as ruas que cruzam a Rivadavia, com exceção das avenidas 9 de Julio e General Paz, trocam de nome depois desse cruzamento. E, mais do que isso, o corte imposto pela avenida é também significativo para a ideia de cidade: se há, em Buenos Aires, múltiplas identidades de bairro, também existe uma divisão mais geral (quase grosseira) entre um sul ainda criollo e um norte moderno. Contraste que já existia nos anos 1940 e que Juan Carlos Onetti leva à literatura no conto "Regreso al sur".

A barreira se mantém erguida para Horacio mesmo depois do ano da separação, que passa a ignorar as imagens e os seres da região sul da cidade. As ruas do sul deixam de ter nome; o comércio e os negócios daquela zona inexistem e não são mais frequentados. Como escreve o narrador, o território situado abaixo da Rivadavia é, para Horacio, formado por "paisagens proscritas". Em meio ao vazio, aparece apenas a imagem (imaginada) de Perla em seu novo mundo, feito de espanhóis que deixaram a guerra e de imersões na boemia de Buenos Aires:

Pero la guerra de España había terminado hacía mucho tiempo, y por muchos meses la Avenida de Mayo fue para Oscar -y él pensaba que también para tío Horacio- diez cuadras flanqueadas de cafés ruidosos en la noche, con hombres y mujeres gordos tomando cerveza en las aceras, mientras a la luz del día muchos toreros iban y venían con paso apresurado. Y las pocas veces en que Oscar atravesó solo de noche Rivadavia y vio una Avenida de Mayo reconocible, volvió sin decir una palabra a tío Horacio y olvidó en seguida lo que había mirado. Así que estaba seguro de que dentro de tío Horacio seguía paralizada la visión fantástica del territorio perdido, donde Perla conversaba y reía y donde era frecuente que hubiese una Perla en cada café ruidoso, cerca de un torero, cerca de un hombre de pelo retinto, inclinado encima de una guitarra (2011, p. 121).

Horacio vence a barreira da avenida Rivadavia como que por distração. Quando Óscar e Walter já estavam habituados aos contornos do tio, que flertava com as ruas do sul e desviava da travessia tão logo se aproximasse das esquinas, o muro pareceu esquecido por um instante: Horacio caminhava e falava com o filho e o sobrinho, contava sobre o que havia lido em livros e revistas no tempo ocioso da pensão, até que atravessou a avenida como se aquela fosse uma caminhada como todas as outras. Andavam pela rua Talcahuano, e desta vez não havia um muro invisível ou uma cerca. Adentraram o universo até então proibido do sul sem tocar no assunto. Horacio continuava a falar enquanto apareciam os primeiros cafés e se podia sentir o ruído de quem caminhava pela Avenida de Mayo. Sentaram-se no terceiro café com música que teve lugar no trajeto. Já à mesa, com uma cerveja para cada um e um sorriso no rosto de Walter e de Óscar, a noite continuava - quando, de súbito, Horacio escorregou da cadeira e levou a mão ao peito. $O$ coração fraquejou na noite da travessia; o ato de transpor a barreira da Rivadavia cobrava, então, o seu preço.

Em "Regreso al sur", Horacio ainda é levado inutilmente para um hospital situado na rua Esmeralda, número 66 , como se pode saber pelo narrador. Trata-se de um ponto próximo ao centro e às primeiras quadras do sul, pertencente a esta zona de fronteira em que ocorre a passagem. O ímpeto da travessia, no relato de Onetti, tem como consequência a morte de Horacio, e as paisagens escolhidas por Perla permanecem, de maneira definitiva, distantes da vida do ex-companheiro. "Regreso al sur", coincidentemente ou não, não é o único relato a utilizar as linhas da cidade de Buenos Aires e a própria avenida Rivadavia como metáforas da travessia e da fronteira. Foi Jorge Luis Borges quem, no conto "El sur", escrito no 
início dos anos 1950 e publicado pela primeira vez em 1953 (posterior, portanto, ao texto de Onetti), escreveu a frase "nadie ignora que el Sur empieza del otro lado de Rivadavia" (BORGES, 1994, p. 81). Também em Borges, ultrapassar a fronteira implica em arcar com os riscos da passagem de um mundo para outro.

O fragmento da história de Juan Dahlmann narrado por Jorge Luis Borges em "El sur" é marcado por diversos deslocamentos: todos eles, no entanto, convergem na direção austral. Dahlmann, funcionário de uma biblioteca que se vê atordoado por uma improvável doença (feriu o rosto ao subir uma escadaria com o exemplar de $A s$ mil e uma noites e então viu a febre crescer), sentia-se intimamente ligado à figura do avô, militar que morreu combatendo na fronteira de Buenos Aires e que deixou como herança a Juan uma estância localizada no sul da província homônima. "Un estuche con el daguerrotipo de un hombre inexpresivo y barbado, una vieja espada, la dicha y el coraje de ciertas músicas, el hábito de estrofas del Martín Fierro, los años, el desgano y la soledad, fomentaron ese criollismo algo voluntario, pero nunca ostentoso" (BORGES, 1994, p. 78), pode-se ler no início da narrativa. A trajetória de Dahlmann em "El Sur" será justamente (ainda que talvez se dê no espaço do delírio) o movimento em direção a essas origens criollas.

Dalhmann fere o rosto na escadaria da biblioteca, localizada na rua Córdoba, e dali é levado para um sanatório na rua Ecuador para que a enfermidade não se prolongue por demais. No entanto, os dias se passam entre a dor, a febre e os pesadelos; estes, diabolicamente decorados pelas ilustrações do recém-adquirido exemplar de As mil e uma noites. O sofrimento e a fraqueza do corpo parecem conduzir o personagem à morte - desfecho que se modifica de forma abrupta quando o narrador indica que o Juan Dahlmann se recompõe dos males e que deve descansar na sua estância, território que até o momento não havia sido visitado por ele. "Verano tras verano se contentaba con la idea abstracta de posesión y con la certidumbre de que su casa estaba esperándolo, en un sitio preciso de la llanura" (BORGES, 1994, p. 79), está dito sobre a estância. Para alcançá-la, será preciso entrar em um trem que parte da estação de Constitución.

Da rua Córdoba para o sanatório da rua Ecuador; do sanatório para a estação de Constitución. Esses deslocamentos se fazem no sentido sul, e atravessam boa parte do território de Buenos Aires. Na última etapa do trajeto, da rua Ecuador para a estação de trens, o "coche de plaza" cruza a avenida Rivadavia: Dahlmann já se encontra em outro território, e a descida continuará. Já em Constitución, o personagem deveria esperar por trinta minutos até a partida do trem. Resolve rumar até um café localizado na rua Brasil (a saída sul da praça de Constitución), "a pocos metros de la casa de Yrigoyen"
(BORGES, 1994, p. 81). O trem em que embarcará - como todos que têm como origem essa estação bonaerense tem como destino o sul da Província de Buenos Aires, este sul ainda mais "antigo e firme" do que o da cidade. A província, ainda rural, é composta por terrenos baldios, estâncias (como a que espera por Dahlmann), armazéns, pátios, ruas de pedra e gauchos que não caminham pelas ruas modernas de Buenos Aires.

É no momento da viagem de Dahlmann que a irrealidade se infiltra com mais força em "El sur". Embora o conto permaneça descrevendo a ida do personagem em direção à estância, distintos elementos colocam em dúvida a saída de Dahlmann do sanatório da rua Ecuador. O ímpeto de viajar e o devaneio de quem convalesce se confundem. O leitor atento não deixará passar, na leitura, a súbita cura de Dahlmann; o estranho almoço servido no trem, em tigelas de metal reluzente, "como en los ya remotos veraneos de la niñez" (BORGES, 1994, p. 82); a sensação (em meio a um sonho?) que viajava não em direção à estância, mas ao passado; a explicação de um funcionário, no vagão, de que aquele trem não pararia na estação de sempre, mas em outra, um pouco anterior, e que se encontrava quase vazia. Para alcançar o objetivo, seria preciso também caminhar por algum tempo. Na caminhada, em que Dahlmann se esforça para encontrar um carro que possa transportá-lo de vez para a estância, o personagem se depara com um armazém de "pobre arquitetura". Entra e confunde o patrão com um dos homens que o atendia no sanatório; no chão, quase na entrada do lugar, se depara com um homem que só poderia ser encontrado naquele sul profundo:

Los muchos años lo habían reducido y pulido como las aguas a una piedra o las generaciones de los hombres a una sentencia. Era oscuro, chico y reseco, y estaba como fuera del tiempo, en una eternidad. Dahlmann registró con satisfacción la vincha, el poncho de bayeta, el largo chiripá y la bota de potro y se dijo, rememorando inútiles discusiones con gente de los partidos del Norte o con entrerrianos, que gauchos de ésos ya no quedan más que en el Sur (1994, p. 85).

Páginas antes, o narrador havia descrito o encontro de Juan Dahlmann com um gato de pelagem negra, no café da rua Brasil, pouco antes de embarcar no trem. A observação do rústico homem no armazém se assemelha, já no sul da província, à imagem do gato: o animal viveria "na actualidad, en la eternidad del instante" (BORGES, 1994, p. 82), ao contrário dos demais homens, que habitariam a sucessão e o tempo. Os acontecimentos no armazém arrastam Dahlmann para um improvável duelo e a estância não será alcançada. "El sur" termina num ponto impreciso do arrabalde bonaerense, longe o suficiente da 
cidade para que se o personagem esteja sob outras regras e outras criaturas - ali estava o tempo antigo e a dureza nas conversações, a parede rústica de um armazém que perdeu a cor e a adaga como o instrumento que preserva a honra e faz surgir o sangue. Ali estava, também, a irrealidade que surge da viagem e da travessia: o preço, como já foi visto em Onetti, de ultrapassar a barreira e de penetrar num território que ora é desconhecido e ora é proibido; território que não pertence a um bibliotecário da cidade de Buenos Aires, mesmo que esteja situado a poucos quilômetros do centro da Capital Federal.

\section{Referências}

ANTÚNEZ, Rocío. Juan Carlos Onetti: caprichos con ciudades. Cidade do México: Gedisa, 2013.

BENJAMIN, Walter. Obras escolhidas II: Rua de mão única. São Paulo: Brasiliense, 1995.
BORGES, Jorge Luis. Artificios. Madri: Alianza Editorial, 1994.

KOHAN, Martín. Zona urbana: ensayo de lectura sobre Walter Benjamin. Buenos Aires: Editorial Norma, 2004.

ONETTI, Juan Carlos. Cuentos completos. Montevidéu: Alfaguara, 2009.

ONETTI, Juan Carlos. El pozo. Madri: Punto de Lectura, 2007.

ONETTI, Juan Carlos. La vida breve. Barcelona: Galaxia Gutemberg, 2013.

ONETTI, Juan Carlos. Tão triste como ela e outros contos. São Paulo: Record, 1989.

SARLO, Beatriz. Modernidade periférica. São Paulo: Cosac Naify, 2010.

Recebido: 16 de abril de 2017

Aprovado: 19 de junho de 2017

Contato:

Iuri Almeida Müller <iuri.muller@gmail.com> 